\title{
A Reading Program Based on the Science of Reading: Can a Multisensory, Systematic, Direct Approach Work?
}

\author{
Carol L. Klages ${ }^{1}$, Mary-Margaret Scholtens ${ }^{2}$, Kelly Fowler ${ }^{3}$, Cheri Fierson ${ }^{4}$ \\ ${ }^{1}$ University of Houston-Victoria, United States \\ ${ }^{2}$ The Apple Group, United States \\ ${ }^{3}$ The Apple Group, United States \\ ${ }^{4}$ The Apple Group, United States
}

\begin{abstract}
The cost of illiteracy and reading difficulties in American society is widely accepted and largely incontrovertible. Being an illiterate adult in the United States can be costly. According to the 2019 National Assessment of Educational Progress (NAEP) or better known as the Nation's Report Card, 35\% of American fourth graders read at a proficient level and 34\% of American eighth graders read at a proficient level. Research compiled for the National Conference of State Legislatures (2020) third graders who are not reading on grade level are most likely to eventually drop out of school. Illiteracy has a monetary influence on people as well. American employers spend $\$ 125.9$ billion dollars to train potential employees in the areas of remedial reading, writing, and mathematic skills (ProLiteracy, 2020). Educators must act on scientific research in order to prevent reading failures. Illiteracy stems from lack of appropriate reading instruction in the early school years. Since reading is not a natural process, literacy must be taught through the lens of the science of reading. Literacy teaching must encompass all the elements and modalities in one comprehensive, research-based program. One such program is from The Apple Group Connections: OG in 3D® (Frierson \& Scholtens, 2014\{Connections $\left.{ }^{\circledR}\right\}$ ) science-based reading. Connections ${ }^{\circledR}$ is an efficacious methodology for addressing reading difficulties with proven reading results.
\end{abstract}

Keywords: curriculum; educators; learning; literacy; teaching; 


\section{ILNAEDUCATION \\ 27-29 March, 2020 \\ Oxford, United Kingdom}

\section{Introduction}

Multiple modalities have been developed to address the process of teaching children to read and address reading difficulties. The most successful, however, are predicated on sciencebased reading instruction and evidence-based approaches. According to The National Reading Panel (NRP) Report (National Institute of Child Health and Human Development \{NICHD\}, 2000) states that effective reading instruction focuses on five critical areas: phonemic awareness, phonics, fluency, vocabulary, and comprehension. While many schools may use different approaches to these five components, the NRP (2000) determined that systematic and explicit instruction is best. Teaching reading effectively, especially to students who are struggling, requires considerable knowledge and skill. A valuable approach for teaching children to read is that of the Connections ${ }^{\circledR}$ program. This program has produced significant reading results for over three years in grades kindergarten, first and second thus, making it a significant research-based literacy program.

While the approaches to teaching reading may vary, the foundation of those approaches cannot. The NRP Report made it very clear that effective reading instruction must address five specific components that are taught systematically and explicitly: phonemic awareness, phonics, fluency, vocabulary, and comprehension (NICHD, 2000). Phonemic awareness is significant to learning an alphabetic language (Wagner, Torgesen, \& Rashotte, 1994). Phonemic awareness is understanding that spoken words consist of separate parts of sound that can be blended together to make words. By measuring the degree to which children develop phonemic awareness, researchers can identify who would learn to read with ease and who would have difficulty (Share, Jorm, Maclean, \& Matthews, 1984). Phonemic awareness plays a significant role in learning to read.

Appropriate phonics instruction supports the skills children need to read and spell words automatically. Jeanne Chall (1967) began important research that supports the systematic phonics instruction. Phonics is more than mastery of simple relationships between letters and sounds but includes lessons in words structure and origins (Moats, 2007). Phonics instruction promotes the relationship between graphemes, which are letters or letter combinations and phonemes which are individual speech sounds. A strong literacy program is not limited to phonics instruction.

Another element in the effective teaching of reading is fluency. Fluency instruction should be built on understanding, "Reading fluency that supports comprehension is built on automaticity in word recognition, accurate word reading, prosody, and expression (Moats \& Tolman, 2009). According to Kilpatrick (2019), “The elusive key to reading fluency is sight word vocabulary'. Without a sight word vocabulary, reading is effortful and often incorrect. Fluency is a product of efficient reading instruction.

An additional product of efficient reading instruction is vocabulary. Vocabulary is the words children must know to communicate with others. Vocabulary encompasses four types: listening, 
speaking, reading, and writing (Learning Point, 2004). Two instructional strategies that improve reading comprehension are based on ongoing, long-term vocabulary instruction (Beck, Perfetti, \& McKeown, 1982) and teaching vocabulary before making a reading assignment (Brett, Rothlein, \& Hurley, 1996; Wixson, 1986). Scarborough (2001) lists breadth and depth as important during vocabulary study. Breadth affects reading comprehension while depth affects fluency (Tannenbaum, Torgeson, \& Wagner, 2006). Vocabulary knowledge is vital to becoming a successful reader.

The fifth element of effective reading instruction is comprehension. Comprehension is understanding what one reads. The content of comprehension is the sum of its parts. Gough and Tunmer (1986) depicted reading comprehension as the sum or word recognition (or decoding), multiplied by language comprehension. Skills upon which comprehension is dependent should be taught. Word reading, vocabulary, syntax, background knowledge, inferencing, and attention are skills that are important for making sense of text (Kilpatrick, 2015). Reading comprehension relies on many covert mental activities. Again, all of the components of effective reading instruction must be taught in a systematic, explicit manner (NRP, 2000). These specific guidelines can be a challenge but are necessary for successful reading instruction.

Systematic instruction is done in a planned, logical progressive sequence (Learning Point Associates, 2004). Certain sounds that are easier to learn should be taught before those that are more difficult. The lesson objectives are clear and specific in terms of what students must be able to do. According to the International Dyslexia Association (2020), the organization of what is taught to students should follow the logical order of the language. Carefully created tasks give students learning opportunities to apply what they have been taught. Any assessments are designed in a timely manner to check skill attainment as well as the application of new skills and their retention over time as students work independently.

Explicit instruction requires that the teacher state clearly what is being taught. The student does not have to guess what he/she is supposed to know from the lesson. Explicit instruction requires teachers to model how a skill is to be used. Carefully created tasks give students learning opportunities to apply what they have been taught (International Dyslexia Association, 2020). In this approach, the student's attention is focused on what is important to know or do. The Connections ${ }^{\circledR}$ reading program is based on the five elements of effective reading instruction that is systematically and explicitly delivered.

Connections: $\mathrm{OG}$ in $3 \mathrm{D} \cap$ is a structured literacy curriculum that systematically teaches the entire structure of the English language. Each lesson provides direct, explicit instruction in the five components of reading, as outlined in the NRP Report (2000). Lessons are cumulative and follow a logical order. The scope and sequence present the alphabetic principle in order of frequency of use, from simplest to most complex. Concepts are taught from concrete to abstract, through handson lessons with 3-D materials. The 3-D materials evolved from the multisensory approach of Orton-Gillingham (Gillingham \& Stillman, 1960, 1997) of teaching reading. Students can "hold" 


\section{LCNAEDUCATION

and manipulate sounds in their hands with 3-D objects. An example of a 3-D object used in this literacy program would be an actual apple. The student would hold this apple, smell the apple, and even taste the apple, if appropriate, in order to learn the short vowel sound of /a/. Connections ${ }^{\circledR}$ follows the principles and content of a multisensory structured language approach. Connections ${ }^{\circledR}$ stands apart from other Orton-Gillingham (Gillingham \& Stillman, 1960, 1997) \{OG\} because it incorporates phonemic objects. By holding the object, which represents the sound he/she is learning, the student can actually "feel" the sound, helping to make more connections to the brain in order to remember that sound. In addition to visual, auditory, tactile, and kinesthetic teaching, Connections ${ }^{\circledR}$ also incorporates teaching sounds by smell and taste, senses that are often overlooked in multisensory programs.

Connections ${ }^{\circledR}$ teaches students to attend to sound, spelling, meaning, and etymology. In addition to phoneme-grapheme correspondence and orthographic mapping, students become aware that the English language is morphophonemic, as layers of etymology and morphology are added.

Application of sound to symbol knowledge, spelling rules and patterns, grammar, comprehension, and fluency are practiced using nonsense words, real words, phrases, sentences, and connected text. $100 \%$ decodable, personalized readers provide decoding practice. Vocabulary (including multiple meanings and figures of speech) is learned by developing semantic networks or ideas and relationships.

To ensure automaticity, frequent distributive practice and checkpoints for mastery are built into each lesson. When decoding becomes automatic, students are able to use their cognitive energy for higher level comprehension. Students learn syntax and semantics using material they are actually able to decode. Connections ${ }^{\circledR}$ gets its name from the connectivity of the neural pathways from orthography, phonology, and semantics, following the research of Seidenberg (2017). The elements of effective reading instruction are "connected" and work together to produce readers.

\subsection{Purpose of Investigation}

The purpose of this investigation is to identify student literacy growth over an academic school year calendar using the science-based, Connections ${ }^{\circledR}$ literacy program in grades kindergarten, first grade, and second grade in two Arkansas elementary schools and one Missouri elementary school.

\section{Participants}

The participants in this investigation were two elementary schools in two different districts in the state of Arkansas as well as one elementary school in the state of Missouri. Each school district had only one elementary school with a differing number of grade levels involved in the Connections ${ }^{\circledR}$ program because only one elementary school was needed in that district or the 


\section{LCNAEDUCATION

elementary school is divided into other campuses, but still classified as an elementary school. Each teacher of kindergarten, first grade, and/or second grade completed the required Connections ${ }^{\circledR}$ training in order to use the program with their students during the school year and /or future school years. The participants were all certified teachers in the state of Arkansas and Missouri who were required by their school district to participate in the training for use in the coming school year.

South Side Bee Branch Elementary School is a kindergarten through $6^{\text {th }}$ grade campus. On their campus, $60 \%$ of the students are considered from low-income homes. The student to teacher ratio is 13:1. The class size is 15 students. The school has an overall campus rating of $\mathrm{C}$ according to state data. For the investigation, kindergarten through second grade used the Connections program.

Blytheville Primary School is a kindergarten to second grade campus. On their campus, $82 \%$ of the students are considered from low-income homes. The student to teacher ratio 14:1. The average class size is 16 students. The school has an overall rating of $\mathrm{D}$ according to state data.

Southwest Elementary School is the only school in this investigation from Missouri. The school is a Pre-Kindergarten to second grade campus. On their campus, 58\% of the students are considered from low-income homes. The student to teacher ratio is $13: 1$. The average class size is 13 . The campus has an accredited rating.

\section{Body of paper}

As researchers seek to gather and address research in how to best teach reading to students, it is important for those involved to establish a snapshot of a literacy program's ability to prepare readers. Evidence must be an essential part of teaching. As such, the Connections ${ }^{\circledR}$ program must assess itself on a regular basis to identify student success as well as those who are not as successful. What matters is the modality of the pedagogical approach taken in addressing learning to read. Science and evidence-based methods are quantitatively superior to those not predicated on consistently replicable approaches. A successful literacy program can only be purposeful if it is preparing students to be readers.

\section{Methods}

For this investigation, the Arkansas elementary school, South Side Bee Branch, involved collected data on their students by using the DIBELS $®$ reading assessment. DIBELS $®$ is an acronym for Dynamic Indicator of Basic Early Literacy Skills. It is a short assessment tool to monitor student success with early literacy skills and reading skills. The use of DIBELS ${ }^{\circledR}$ can identify if a child is going to struggle with learning to read (Center on Teaching and Learning (n.d.). In order to 


\section{LCNAEDUCATIION

determine that Connections ${ }^{\circledR}$ represents a scientific pathway to teaching students how to read, it is necessary to analyze objective data from whole-class applications in school districts which have adopted Connections ${ }^{\circledR}$.

Blytheville Elementary school assessed their students using the IStation (n.d.) reading assessment. This assessment tool measures reading ability as well as identifies reading deficiencies based on given student responses. Skills can be measured across different grade levels, kindergarten through eighth grade as it is computer-adaptive in nature.

Southwest Elementary from Missouri used the aimswebPlus (n.d.) assessment tool by the Pearson Company to monitor student progress in reading and mathematics. For this investigation, only the reading reports were used. The students take the assessment primarily online and the results are reported in real time. Common Core Standards and state standards are aligned within the assessment process. The data is reported three times a year. For this investigation, only the fall or beginning of the school year reports and the spring or end of the school year reports were used. The results are reported in a Tier 1, Tier 2, and Tier 3 risk level. Tier 1 is a low risk for reading failure, Tier 2 is a moderate risk for reading failure, and Tier 3 is a high risk for reading failure.

\section{Results}

South Side Bee Branch Elementary School participated in the Connections ${ }^{\circledR}$ program in grades Kindergarten through second grade. The year they used the program was 2018-2019 school year. The 2019-2020 results have not been completed as yet. The results were assessed with the DIBELS assessment tool.

Students in the kindergarten class of 2018-2019 were assessed eighteen times throughout the school year. There was no assessment report that indicated any negative growth. At every assessment period the growth at least doubled. At the end of the school year, eighty-three percent of the class was reading on grade level and seventeen percent below grade level. These results were better than the state average.

The first-grade classroom experienced similar results. This group was assessed twenty times throughout the school year. At the end of the year, seventy percent of the students were reading on grade level and thirty percent were below grade level. These results were better than the state average.

The second-grade classroom was assed fifteen times over the course of the 2018-2019 school year. Their results were similar to those of the previous two grade levels. At the end of the school year, eighty percent of the students were reading on grade level and twenty percent were below grade level. These results were better than the state average. 


\section{ILNAEDUCATION \\ 27-29 March, 2020 \\ Oxford, United Kingdom}

Southwest Elementary school in Missouri started the Connections ${ }^{\circledR}$ program with second grade students in the school year 2018-2019. Their entire school year was reported. In the fall, 55\% of the students were at Tier 1, 28\% of the students were reported at Tier 2, and $17 \%$ of the students were reported at Tier 3 .

In the spring, $84 \%$ of the students were reported at Tier $1,5 \%$ were reported at Tier 2 , and $11 \%$ were reported at Tier 3. At the end of the academic year, Tier 1 experienced $60 \%$ growth which means less students are at risk for reading failure. Tiers 2 and 3 also experienced positive changes. In the fall $45 \%$ of the students were either at moderate for high risk for reading failure. At the end of the academic year, only $16 \%$ were at moderate or high risk for reading failure therefore, $166 \%$ positive change for the those with reading struggles.

Because the second- grade class showed such incredible reading growth in the previous school year, kindergarten and first grade were added to those students receiving reading with the Connections program in the 2019-2020 school year. As the school year is still in progress at the time of this article, the results are for the fall, or beginning of the school year and the winter break, which is in December. The spring results will be added to this article as they are available. The first results to share are for the kindergarten group. In Tier 1, 25\% of the students are at low risk of reading failure. For Tier 2, $18 \%$ are at a moderate risk for reading failure and Tier 3, the highest risk of reading failure was $57 \%$ of the class.

The winter assessment results identified $42 \%$ of the class was now at a low risk of reading failure. Tier 2 had 30\% at moderate risk of reading failure and Tier 3, the highest risk of reading failure was now $28 \%$. The positive growth rate for those at Tier 1 was now $42 \%$ which is a $63 \%$ change from the fall assessment. Those students in Tiers 2 and 3 with the highest risks of reading failure where now 58\% change. As such, Tiers 2 and 3 showed positive growth in reading by $34 \%$ over a few months period of time.

The first- grade class also showed positive results. Again, these results are for the fall and winter assessment period of the 2019-2020 school year. In the fall assessment period, $48 \%$ of the students were identified as Tier 1. Students identified as Tier 2 for the fall semester totaled $12 \%$, and $40 \%$ students were recorded as Tier 3.

The winter assessment results are as follows: $55 \%$ at Tier $1,14 \%$ at Tier 2, and $31 \%$ identified at Tier 3. For the Tier 1 students, that is an $11 \%$ increase in the number of students who are now considered to be at low risk for reading failure which means some students moved from either the second or third tiers which are identified to be at a moderate or his risk of reading failure. Tiers 2 and 3 also so showed positive growth. Students moved from Tier 3, which is a high risk for reading failure into the Tier 2 category which is moderate risk. 
The second grade at Southwest elementary continued their use of the Connections ${ }^{\circledR}$ program. Their results for the 2019-2020 school year are positive again. In the fall assessment report, 59\% of the students were identified Tier 1 . For Tier 2, $21 \%$ of the second graders were at a moderate risk for reading failure. In Tier 3, $20 \%$ of the students were at high risk for reading failure. In December 2019, the winter assessments were given. $69 \%$ of the students were assessed at Tier 1. $19 \%$ of the students were identified at Tier 2 , and finally, $12 \%$ of the students were identified at Tier 3. For Tier1, that is $16 \%$ positive growth in the number of students who are now at low risk for reading failure. For Tiers 2 and 3, the growth was 32\% who moved out of the higher risk tiers.

The kindergarten and second- grade classes at Blytheville elementary all participated in the Connections ${ }^{\circledR}$ reading program in school years 2018-2019 and 2019-2020. Kindergarten was assessed in letter knowledge and phonemic awareness (two important aspects of learning to read) using the IStation reading assessment. The second -grade class was assessed in spelling using the IStation reading assessment. Beginning in September to February, every month of the 2018-2019 and 2019-2020 school years were assessed except the month of October for the kindergarten class.

In the 2018-2019 school year the kindergarten class saw $20 \%$ of the students mastering letter knowledge. In November, $22.5 \%$ mastered it. December saw $45 \%$ of the students mastering letter knowledge. January so a downturn to $40 \%$, but February was back up to $45 \%$.

When the 2018-2019 school is compared to the next school year 2019-2020, the positive growth becomes more evident. In September, $20 \%$ mastered the letter knowledge needed to learn to read. November saw $45 \%$ of the students mastering that knowledge. In December the growth continued with $50 \%$ of the students able to identify letters needed for reading. Again, in January a dip occurred down to $45 \%$, but it rose in February to $68 \%$.

The kindergarten class was assessed in phonemic awareness in 2018-2019 and 2019-2020 school years. In the 2018-2019 school year, the results are as follows: $28 \%$ of the students met the criteria for phonemic awareness needed in order to read. Again, in October no testing was done. November saw assessment remain the same in terms of percentage points. December and January $40 \%$ of the students possess phonemic awareness skills. February that percentage rose to $45 \%$ of the students. No negative results were reported in terms of phonemic awareness skills.

In the 2019-2020 school year the kindergarten students had to demonstrate their phonemic awareness skills. September $31 \%$ of the students demonstrated proficiency in phonemic awareness skills. November $43 \%$ and December $45 \%$. January when assessed again, there was a slight drop in percentage points to $43 \%$. In February, the percentage points rose again to $50 \%$ proficiency in phonemic awareness skills.

The Blytheville Elementary second graders were assessed in the school years 2018-2019 and 20192020. They were assessed on their spelling knowledge. The 2018-2019 scores are as follows: September 35\%, October 40\%, November 44\%, December 45\%, January 42\%, and February $45 \%$. 


\section{LINAEDULATION \\ 27-29 March, 2020 \\ Oxford, United Kingdom}

The spelling assessment for the Blytheville in the next year are as follows: September $42 \%$, October 56\%, November 46\%, December 45\%, January 47\%, and February $47 \%$. The second graders were assessed during the month of October unlike the kindergarten class.

\section{Discussion}

Overwhelmingly, the results when using the Connections ${ }^{\circledR}$ program are significant. Each individual grade level at each of the elementary schools saw reading growth from the previous school year when using the Connections ${ }^{\circledR}$ reading program. The change in reading on grade level saw significant growth at each grade level for each school.

The students at Blytheville Elementary were not consistently assessed in the month of October, so that data was not provided to the investigation. For the kindergarten students, the month of January reported a slight negative dip in the scores of letter knowledge and phonemic awareness for both school years. As the students are off for almost two and a half weeks from school, they are not consistently reviewing and addressing their letter knowledge and phonemic awareness skills. The scores rebounded in the month of February and were even larger than that of the December scores.

The growth in spelling skills for the second graders from the beginning of each school year to middle of the next semester is overall positive with the exception of December to January of 20182019 and October to November of 2019-2020. The dip in skills from December to January of 2018-2019 could be attributed to the winter break that students have for close to two- and one-half weeks where they did not actively practice those specific skills. The dip in percentage points for the month of January 2019-2020 school year is attributed to the same reason as stated previously; winter break with the time of from school. Again, the scores rose in February.

The Connections: $O G$ in $3-D \circledast$ reading program supports the science of teaching reading in a systematic, direct manner. Each teacher taught the program in the same manner, with the same materials, objects, lessons, and sequencing. As the program teaches to mastery, the students may need different amounts of time to be successful, but the score results indicate positive results.

It is significant to note that regardless of the school's demographic data, every school involved in this research investigation, students produced close to or at double digit growth in their reading on grade level scores when the Connections ${ }^{\circledR}$ reading program was used to teach them to read. The score results for all students involved with learning to read via the Connections ${ }^{\circledR}$ program were higher than the average state scores in both Arkansas and Missouri. 


\section{SICNAEDUCATION \\ 27-29 March, 2020 \\ Oxford, United Kingdom}

\section{Conclusion}

Research efforts must be on-going. As other school districts adopt the Connections® program, their assessment data will be reviewed and shared. As this research effort was in progress, schools in two other states, Pennsylvania and Minnesota, have selected the Connections: OG in 3D®program as the tool for teaching reading. As the demographic information in states differs as well as their reading needs, comparing assessments from those states can solidify the success of the science-based reading program; Connections ${ }^{\circledR}$.

The ability to read is too precious a skill to allow any students to fail at the task. As more and more students learn to read, regardless of personal background or socio-economic level, the propensity within the education system to embrace teaching fads and unproven programs must offer a way to more effective practice of teaching students to read on a more evidenced- based foundation. The science of reading is solid scientific research on how reading should be taught. The Connections ${ }^{\circledR}$ program was developed on that scientific research. Student reading success has been proven based on solid effective reading practices that Connections ${ }^{\circledR}$ utilizes. Because anyone who does not learn to read will face challenges continuing on in school as well as in their lives, the education system must do everything in its power to teach students to read. Based on recent evidence, the Connections: $\mathrm{OG}$ in $3-\mathrm{D} \AA$ reading program has proven that students can learn to read.

\section{Acknowledgment}

This paper is an output of the work of educators, reading therapists, researchers, and school administration. Without the dedicated service of educators, administrators, and all those who care that students learn to read, there would be no child eager to pick up a book and read.

\section{References}

Beck, I., Perfetti, C., \& McKeown, M. (1982). Effects of long-term vocabulary Instruction on lexical access and reading comprehension. Journal of Educational Psychology, 74 (4), 506-521.

Brett, A., Rthlein, L., \& Hurley, M. (1996). Vocabulary acquisition from Listening to stories and explanation of target words. Elementary School Journal, 96 (4), 415-422. 
Center on Teaching and Learning (n.d.). UO: DIBELS Data System. Retrieved February 10, 2020. Dibels.uoregon.edu

Chall, J. (1967). Learning to read: The great debate. New York: McGraw Hill.

Frierson, C. \& Scholtens, M. (2014). Science-based reading connections: OG in 3D. Jonesboro, AR: The Apple Group

Gillingham, A. \& Stillman, B.W. (1960). Remedial training for children with specific disability in reading, spelling, and penmanship $\left(6^{\text {th }}\right.$ ed.).

Cambridge, MA: Educator's Publishing Service.

Gillingham, A. \& Stillman, B.W. (1997). The Gillingham manual: Remedial training for children with specific disability in reading, writing, and penmanship ( $8^{\text {th }}$ ed.) Cambridge, MA: Educators Publishing Service.

Gough, P.B., \& Tunmer, W.E., (1986). Decoding, reading, and reading Disability. Remedial and Special Education, 7(1), 6-10. Doi 10.1177/074193258600700104.

International Dyslexia Association (2020). Effective Reading Instruction. https://dyslexiaida.org/effective-reading-instruction/ Retrieved February 10, 2020.

IStation Reading (n.d.). Powerful research-based assessments and instruction based on the science of reading and the Big Five. https://www.istation.com/Reading Retrieved February 19, 2020.

Kilpatrick, D.A. (2015). Essentials of assessing, preventing, and overcoming reading difficulties. Hoboken, NJ: John Wiley \& Sons.

Kilpatrick. Kilpatrick, D. (2019). Recent Advanced in Understanding Word Level Reading Problems: Implications for Instruction and Intervention. Paper presented at the 47th Arkansas Literacy Conference, Little Rock, Arkansas. Retrieved from https://www.slideplayer.com/slide/17795239/

Learning Point Associates, (2004). A closer look at the five essential components of effective reading instruction: A review of scientifically based reading research for teachers. ED-01-CO-0046/0001. Retrieved February 9, 2020. 
Moats, L.C., Tolman, C. (2009). Language Essentials for Teachers of Reading And Spelling: Module 5 Getting Up to Speed: Developing Fluency, Second edition. Dallas, TX: Sopris West Educational Services.

Moats, L.C. (2007). Whole language high jinks: How to tell when "scientifically-based reading instruction" isn't. Thomas B. Fordham Institute. (ERIC Document Reproduction Service No. ED 498005).

Moats, L.C., (2017). Can prevailing approaches to reading instruction accomplish the goals of RTI? Perspectives on Language and Literacy 37 (4), 21-24.

National Conference of State Legislatures (2020). https://www.ncsl.org/research/education/pre-kindergarten-third-grade-literacy.aspx Retrieved February 10, 2020.

National Institute of Child Health and Human Development. (2000). Report Of the National Reading Panel. Teaching Children to read: An Evidence-based assessment of the scientific research literature on reading And its implications for reading instruction: Reports of the subgroups (NIH Publication No. 00-4754). Washington, D.C: U.S. Government Printing Office.

Pearson. (n.d.) aimswebPlus. https://www.pearsonassessments.com/store/usassessments/en/Store/ProfessionalAssessments/AcademicLearning/Brief/aimswebPlus/p/100000519.html Retrieved February 17, 2020.

ProLiteracy (2020). Adult Literacy Facts. https://proliteracy.org/Adult-Literacy-Facts Retrieved February 10, 2020.

Tannenbaum, K. R., Torgesen, J. K., \& Wagner, R. K. (2006). Relationships between word knowledge and reading comprehension in third grade children. Scientific Studies of Reading, 10(4), 381-398.

Scarborough, H.S. (2001). Connecting early language and literacy to later reading (dis) abilities: Evidence, theory and practice. In S. Neuman \& D. Dickinson (Eds.), In Handbook for Research in Early Literacy (pp. 97-110). New York: NY Guilford 
Press.

Share, D., Jorm, A., Maclean, R., \& Matthews, R. (1984). Sources of individual differences in reading acquisition. Journal of Educational Psychology, 76 (6), 1309-1324.

Seidenberg, M. (2017). Language at the speed of sight: How we read, why so many can't, and what can be done about it. NY: Basic Books.

The Nation's Report Card (2019). 2019 NAEP Reading Assessment https://www.nationsreportcard.gov/highlights/reading/2019/ Retrieved February 9,2020.

Wagner, R., Torgesen, J., \& Rashotte, C. (1994). Development of reading-related Phonological processing abilities: New evidence of bi-directional causality From a latent variable longitudinal study. Developmental Psychology, 30 (1), 73-87.

Wixson, K. (1986). Vocabulary instruction and children's comprehension of basal stories. Reading Research Quarterly, 21(3), 317-329. 